\title{
Energy-balance and Sliding Mode Control Strategies of a Cascade H-Bridge Multilevel Converter for Grid-connected PV Systems
}

\author{
Juan José Negroni \\ Universidad Tecnológica \\ Metropolitana, Electronic \\ Engineering Department \\ Santiago, Chile \\ juan.negroni@utem.cl
}

\author{
Domingo Biel \\ UPC- Electronic \\ Engineering \\ Department \\ Vilanova i la Geltrú, \\ Spain \\ biel@eel.upc.edu
}

\author{
Francesc Guinjoan \\ UPC- Electronic \\ Engineering Department \\ Barcelona, Spain \\ guinjoan@eel.upc.edu
}

\author{
Carlos Meza \\ Costa Rica Institute of \\ Technology, Electronic \\ Engineering School \\ Cartago, Costa Rica \\ cmeza@ietec.org
}

\begin{abstract}
This work presents the design of a sliding-mode based current controller for a Cascade Full Bridge Multilevel Inverter grid connected PV system. The design also includes a modulation strategy to share the control action among the cascade-connected bridges in order to concurrently synthesize a multilevel waveform and to keep each of the PVG at its maximum operating point. Experimental results are included to validate the proposed approach.
\end{abstract}

\section{INTRODUCTION}

Photovoltaic (PV) electrical energy generation provides several advantages with respect to other conventional energy sources (e.g. coal, nuclear): it uses the inexhaustible world-wide available sunlight as a source of energy, it does not generate environmental pollutants (e.g. CO2) and the PV panels used require minimum maintenance. Photovoltaics has been initially used in stand-alone applications, nevertheless, PV systems that supply energy directly to the utility grid (also referred as gridconnected PV systems) are becoming more popular because of the cost reduction due to the lack of a battery subsystem. Moreover, governmental laws and policies recently created that favors grid-connected PV (GPV) systems have proved to be an effective way to encourage the use of solar energy. The high cost per watt of PV energy compared to other energy sources has motivated the current research in this area, focusing mainly on activities that

1) improves the efficiency of PV cells/panels,

2) reduces the manufacturing costs of $\mathrm{PV}$ cells/panels,

3 ) increases the efficiency of the associated power stage.

The present paper deals only with the later alternative for GPV systems. The power conditioning stage is an essential part of the PV system since it must account for an optimal energy transfer from the energy source to the load [1]. A PV panel or group of PV panels linked to a power unit is referred in this document as photovoltaic generator (PVG). Normally, it is not advantageous to have a unique PVG, i.e., only one big group of PV panels connected to a power unit. For instance, under different operating conditions the energy extraction can be maximized forming PVGs comprise of PV panels with similar conditions [2]. A power converter topology that can link several PVGs to the utility grid is the so-called cascade H-bridge multilevel converter [3-5]. Besides allowing having a maximum power point tracker (MPPT) for each PVG this topology allows reducing the injection of harmonics to the grid.

One of the main antecedents related with the control of such PV inverter topology can be found in [5], where the following control blocks can be formally distinguished:

a) On the DC side a linear PI continuous-time voltage controller is designed to fix each PVG at its maximum power operating point.

b) On the AC side, a PI or Proportional+Resonant (PR) linear current controller is designed to track the output voltage sinusoidal reference ensuring a unity power factor injection.

c) The use of a PSC-PWM (Phase Shifted Carrier PWM) [6] which generates the DC-AC multilevel conversion and assigns a control signal to each bridge by means of weighting the current controller output by a factor proportional to the available power of the corresponding PVG.

More recently, an energy balance sampled data model has been established to systematically design a digital PI voltage loop ensuring the system's stability in the framework of gridconnected PV systems with a single central inverter [7]. The aforementioned approach was also applied to the cascade-full bridge inverter topology where a linear $\mathrm{P}+\mathrm{R}$ current controller and PSC-PWM modulation have been used [8]. However, since the linear current controller is designed from the linear model of system's AC side, its robustness strongly depends on the model's validity range. Alternatively, this work is devoted to design a sliding-mode based current controller accounting for 
the robustness properties of this control technique. This design also entails developing a modulation strategy to share the control action among the cascade-connected bridges in order to concurrently synthesize a multilevel waveform and to keep each of the PVG at its maximum operating point. After describing the main goals of the control strategy in section II, the voltage control based on the energy-balance model is revisited in section III. Subsequently, the sliding-mode based current controller design and the multilevel waveform synthesis are presented in section IV. To validate the proposed approach, Section $\mathrm{V}$ presents a set of experimental results carried out on two cascaded full bridge inverters linking two solar array emulators to the grid as well as some concluding remarks.

\section{DESCRIPTION OF THE CONTROL StRATEGY}

Fig. 1 shows the generalized power converter structure used to interface the photovoltaic array with the power grid. It consists of $n$ full-bridges with their AC outputs connected in series. This converter structure synthesized an output voltage $V_{H T}$ with $1+2 n$ levels, reducing common-mode disturbances and voltage harmonics amplitudes.

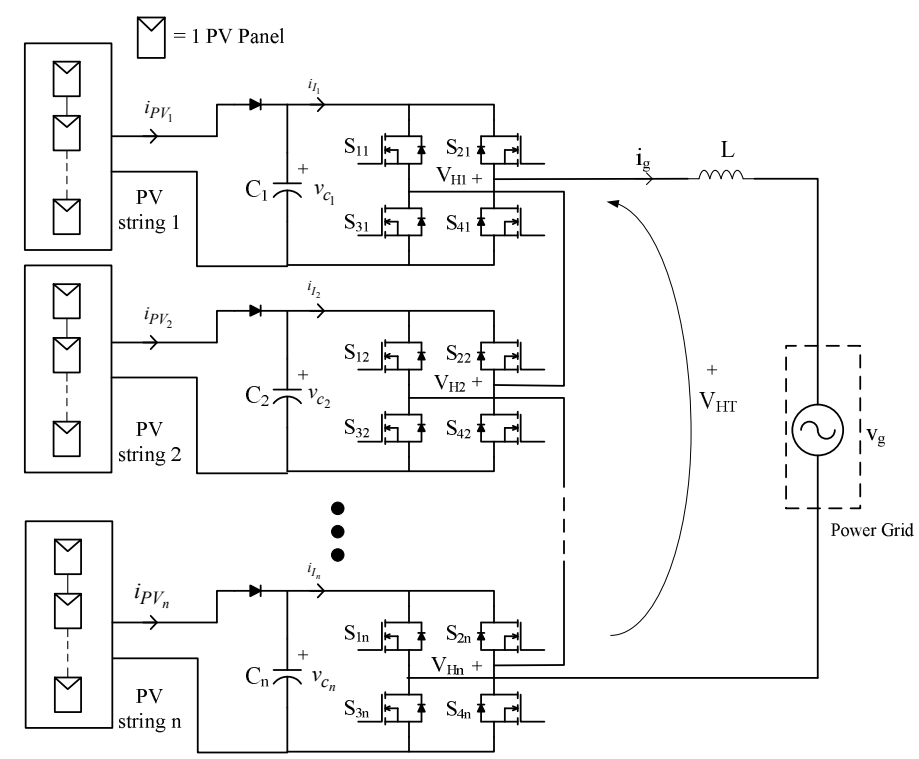

Figure 1. Power conditioning system's circuit.

Defining $u_{i} \in\{-1,1\}$ as the control signal that manages switches $S_{1 i}, S_{2 i}, S_{3 i}$ and $S_{4 i}$ the system can be represented by the following set of differential equations:

$$
\begin{aligned}
& \frac{d v_{c_{i}}}{d t}=\frac{1}{C_{i}}\left(i_{P} V_{i}-i_{g} u_{i}\right) \\
& \frac{d i_{g}}{d t}=\frac{1}{L}\left(\sum_{i=1}^{n} v_{c_{i}} u_{i}-v_{g}\right)
\end{aligned}
$$

for $i=1$ to $n$, where $n$ is the total number of H-bridge converters connected in series.

The control strategy for the cascade H-bridge multilevel PV converter is based on the control scheme described in [7] and extended in order to fulfill the requirements for this specific case, i.e., the control signals for the H-bridge multilevel PV converter have to be generated such that

1. the voltage of each PV string is set to a desired reference value (normally given by a maximum power point tracking (MPPT) algorithm),

2. a unity power factor and low harmonic distortion current is injected to the utility grid, and,

3. a multilevel step-like AC wave voltage is synthesized at the output of the converters.

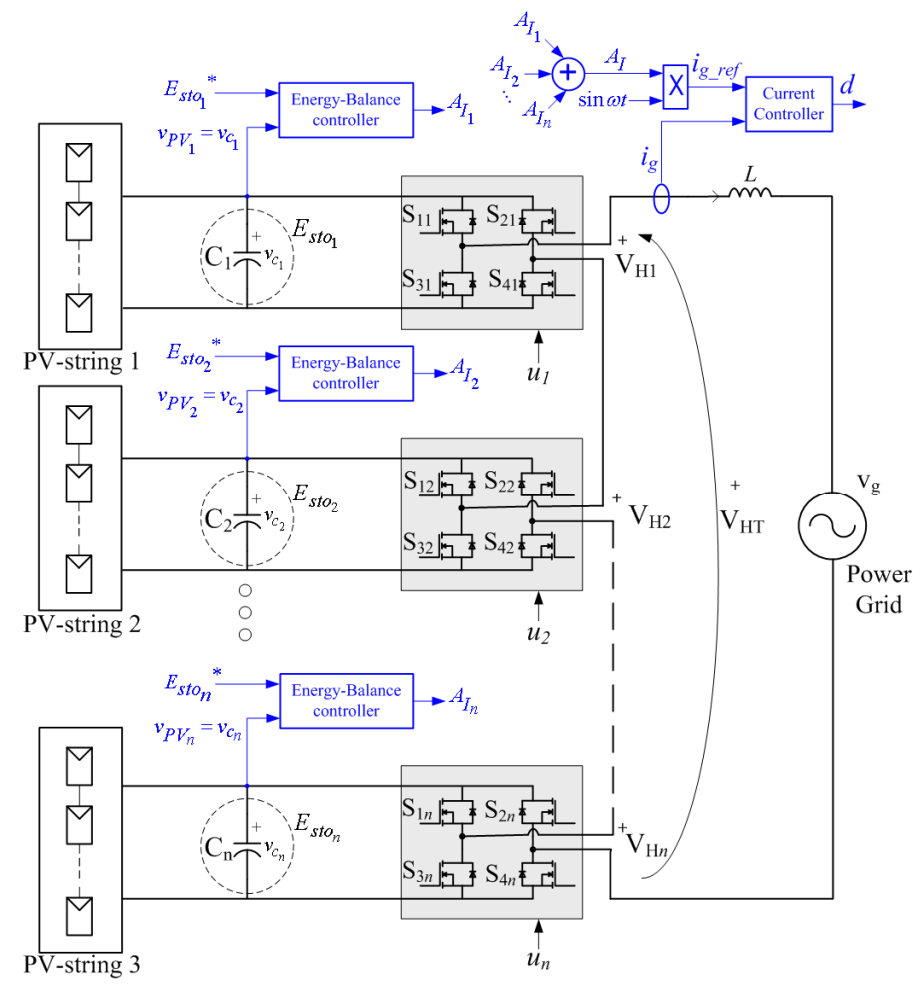

Figure 2. Control scheme.

In order to accomplish the aforementioned objectives a control scheme, shown in Fig. 2, is designed based on the energy sampled data model described in [8]. This model relates the energy stored $\left(E_{S t o_{i}}\right)$ in the capacitors $\left(C_{i}\right)$ with the energy generated by the PV arrays and the energy transferred to the grid. Furthermore, the model states that when the system injects a sinusoidal current to the grid it is possible to set a desired PV voltage by controlling the energy stored in each capacitor. That is why in the scheme of Fig. 2 every H-bridge converter has its own controller in charge of regulating the energy stored in the capacitor to a desired value that can be given by a MPPT. Note that in the diagram of Fig. 2 and in the present article no specific MPPT is considered, it is assumed that one of the widely known MPPT algorithms are used, e.g. [9], to obtain the desired PV voltages $\left(v_{p v_{i}}=v_{c_{i}}\right)$ and consequently $E_{\text {sto }_{i}}$, see (3).

The energy-balance controllers output their correspondent fraction $\left(A_{I_{i}}\right)$ of the injected current amplitude which sum 
results in the reference value of the output current $\left(A_{I}\right)$. A sliding mode current controller makes the output current track its reference value.

\section{ENERGy BALANCE Voltage CONTROL REVISITED}

Define $P_{P V_{i}}$ as the power extracted from the $i$-th PVG, $P_{\text {out }}$ as the output power injected to the utility grid, $E_{P E}$ as the energy stored in the inductor and $E_{S t o}$ as the energy stored capacitor associated to the $i$-th PVG, i.e.,

$$
E_{s t o_{i}}=\frac{C v_{c_{i}}^{2}}{2}
$$

Consider the instantaneous power equation of the system

$$
\frac{d}{d t}\left(\sum_{i=1}^{n} E_{\text {sto }}\right)=\sum_{i=1}^{n} P_{P V_{i}}-P_{\text {out }}-\frac{d}{d t} E_{P E}
$$

where $n$ is the total number of PVG. Assuming a $T$-periodic output current and following the procedure described in [7] it is possible to obtain a $T$-Sampled-Data Model of the system, where $T$ is the utility grid period, yielding,

$$
\begin{aligned}
\sum_{i=1}^{n} E_{\text {Sto }}(k T) & =\sum_{i=1}^{n} E_{\text {Sto }}((k-1) T)+\sum_{i=1}^{n} E_{P V_{i}}((k-1) T) \\
& -0.5 A_{I}((k-1) T) A T
\end{aligned}
$$

where $k=0,1,2,3, \ldots$ represents subsequent grid periods, $A$ is the amplitude of the utility grid period, $A_{I}$ is the amplitude of the output current, and $E_{P V_{i}}$ is the energy extracted from the $i$-th PVG during one grid period. Notice that if, during one grid period, $E_{\text {sto }}$ is kept constant, all the power generated by the PVGs will be delivered to the grid, this resulting in a proportional relationship between the PV power and the amplitude of the injected current, i.e:

$$
\sum_{i=1}^{n} E_{P V_{i}}(k T)=\frac{A_{I}((k-1) T) A T}{2}
$$

Notice that if $E_{P V_{i}}$ corresponds to the maximum available power of each PVGs the maximum power transfer is ensured. Therefore, by controlling the energy stored in the capacitors it is possible to regulate each PVGs' voltage to a desired value.

The control of the storage energy $E_{\text {sto }}$ can be designed from the Sampled-Data Model of the system given by the Ztransform of the linearized version of (5), i.e:

$$
\sum_{i=1}^{n} E_{\text {Sto }}(z)=\frac{1}{z-1}\left(\sum_{i=1}^{n}\left(E_{P V_{i}}^{*}+m_{i}\left(E_{\text {sto }}(z)-E_{\text {Sto }}^{*}\right)\right)+\frac{A_{I}(z) A T}{2}\right)
$$

where each non-linear function $E_{P V_{i}}$ has been linearized around $E_{S t o_{i}}^{*}$ as described in [7] and

$$
m_{i}=\left.\frac{d E_{P V_{i}}}{d E_{\text {Sto }}}\right|_{E_{\text {sto }}}=E_{\text {Sto }}^{*} \text {. }
$$

If the amplitude is decomposed in components associated to each multi-inverter stages, i.e., $A_{I}=\sum A_{I_{i}}$, (7) can be rewritten as a system of $n$ equations, as shown next,

$$
\sum_{i=1}^{n} E_{S t o_{i}}(z)=\frac{1}{z-1}\left(\sum_{i=1}^{n}\left(E_{P V_{i}}^{*}+m_{i}\left(E_{S t o_{i}}(z)-E_{\text {Sto }}^{*}\right)+\frac{A_{I_{i}}(z) A T}{2}\right)\right)
$$

The linear model of (8) enables to regulate the storage energy $\sum E_{S t o_{i}}$ to a desired value $\sum E_{S t o_{i}}{ }^{*}$ by designing a linear controller $G_{C_{i}}$ depicted in Fig. 3.

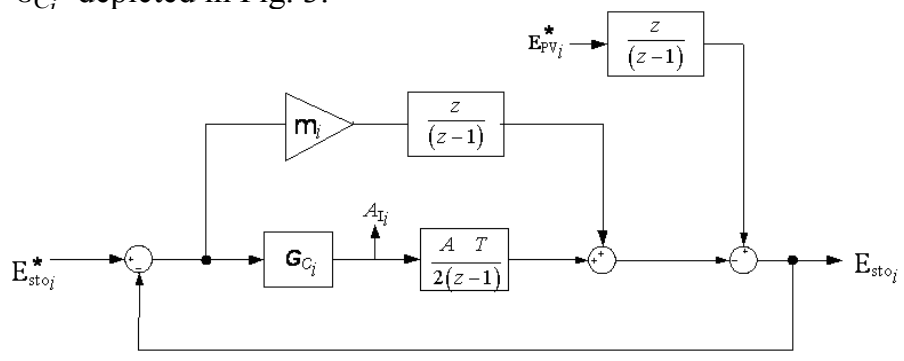

Figure 3. Block diagram of the energy-balance control.

A simple set of linear controllers such as

$$
G_{C_{i}}(z)=\gamma_{i} \frac{z-\alpha_{i}}{z-1}
$$

where $\alpha_{i}$ and $\gamma_{i}$ are parameters of the controllers, allows to successfully regulate the energy stored in the capacitors. The procedure to choose these parameters is taken from [7], i.e., $\alpha_{i}$ is located close to 1 in order to minimize the unstabilizing effect introduced by the integral element and the value of $\gamma_{i}$ is selected such that the closed-loop system is stable (e.g., by applying the Jury test to the characteristic polynomial).

Notice that to ensure that for each capacitor $E_{s t o_{i}}=E_{s t o_{i}}{ }^{*}$ it is necessary to perform additional control actions in the multilevel's modulator.

\section{SLiding CurRent Controller AND Multilevel SYNTHESIS}

The aforementioned control strategy allows obtaining the current amplitude required to extract the maximum amount of energy from the PV panels. This strategy assumes that the current is sinusoidal in phase with the utility grid voltage. It is necessary to design a robust and fast inner current controller to assure this sinusoidal current condition. A sliding mode controller technique has been chosen for the inner current controller given that it has shown good performances in buckbased inverters in front of voltage and load disturbances [10].

The inner controller uses the following switching surface:

$$
\sigma:=i_{\text {gref }}-i_{g}=0
$$

being $i_{g r e f}=A_{I}(k T) \sin (\omega t)$ and $v_{g}=A \sin (\omega t)$.

The multilevel converter operates by switching only one $\mathrm{H}$ Bridge whereas the others remain in fixed ON or OFF state depending on the relationship between the capacitor voltages and the grid voltage. In fact, the control policy guaranties that the overall capacitor voltage is greater (lower) than the positive (negative) grid voltage. Consequently, for instance, if the grid voltage accomplishes $v_{c_{1}}<v_{g}<v_{c_{1}}+v_{c_{2}}$, the first H-bridge will be in $\mathrm{ON}$ state whereas the sliding control law will be applied to the second one. Assuming these premises the control law is given by: 


$$
\begin{aligned}
& u_{i}=0.5(1+\operatorname{sign}(\sigma)) \text { when } v_{g}>0 \\
& u_{i}=-0.5(1+\operatorname{sign}(\sigma)) \text { when } v_{g}<0
\end{aligned}
$$

In order to regulate the capacitor voltage (PV array voltage) to the reference value, the control law is temporally assigned by considering the outputs of the corresponding energy-balance controllers $\left(A_{I_{i}}(k T)\right)$. In case of a multilevel converter composed by three H-bridges, the temporal distribution can be schematized as shows Fig. 4.

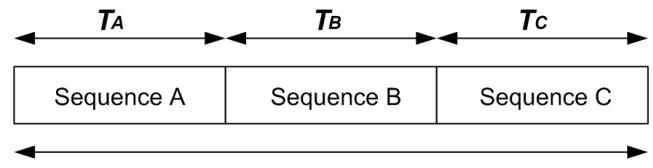

$\operatorname{Tr}$

Figure 4. Scheme of sequence assignation.

where: $T_{A}=T_{r} \cdot \frac{A_{I_{1}}}{A_{I}} ; T_{B}=T_{r} \cdot \frac{A_{I_{2}}}{A_{I}} ; T_{C}=T_{r} \cdot \frac{A_{I_{3}}}{A_{I}}$.

Each sequence considers one H-bridges combination where the H-bridge associated to the energy-balance controller output $\left(A_{I_{i}}(k T)\right)$ is in the lower level. For instance, B sequence implies the use of the combination 2, 3, 1 (where each number corresponds to one H-bridge) as shown in Fig. 5, whereas $\mathrm{C}$ and A sequence are given by 3,1,2 and 1,2,3, respectively.

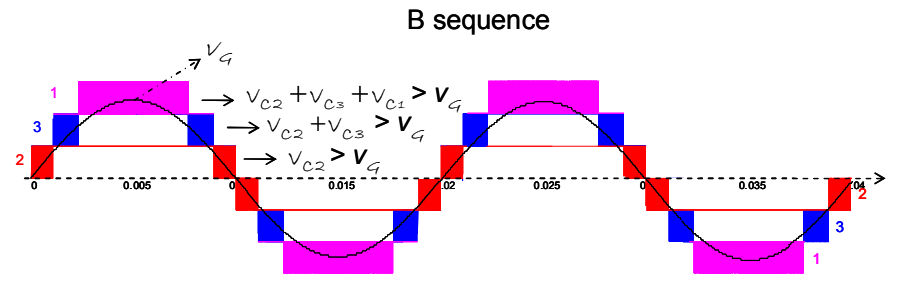

Figure 5. Example of the B-sequence.

\section{EXPERIMENTAL RESULTS AND CONCLUSIONS}

This section applies the presented approach to design the control loops of a laboratory prototype PVG multilevel inverter for subsequent experimental validation purposes. A block diagram of the laboratory prototype is presented in Fig. 6. The experimental setup consists of a five level power inverter with passive elements. Two Solar Array Simulators (SAS) (Agilent E4350B \#J02) delivering maximum output voltages of $80 \mathrm{~V}$ were used to program the PV array electrical characteristics. Due to the SAS low output voltage level, the GPV multilevel inverter prototype was connected to the grid by means of a stepup power transformer. All the measurements were done in the low-voltage side of the transformer, which exhibits a voltage amplitude of $33 \mathrm{~V}$ at $50 \mathrm{~Hz}$.

\section{A. Control Design}

The control scheme was implemented in a field programmable gate array (Xilinx Spartan 3E) and comprises an outer loop controller, such as the one explained in Section III, and a sliding mode inner loop controller, as mentioned in Section IV. Focusing on the outer loop, the parameter $\alpha$ needs to be set to a value close to 1 to mitigate the instability effect of the integral component of $G_{C}$. Therefore $\alpha$ has been fixed to 0.875 .

On the other hand, the design of the controller gain $\gamma \psi$ is strongly related with system stability. As shown in Section IIIA, the stability of the closed-loop GPV system is determined by the parameter $m$ and the controller $G_{c}$. The value of parameter $m$ depends on the input capacitance and the electrical characteristics of the PV array. The maximum value of $m$ (worst case) is required to choose the gain $\gamma$ of the outer loop controller $G_{C}$ and to assure the stability of the closed-loop system in the whole range of operation, as can be derived from (8) and (9). For the experimental system a value of $\gamma=-0.05$ assures the stability of the system under a sufficiently large operating range.

\section{B. Experimental Results}

A series of experimental tests have been carried out to validate the proposed control scheme.

1) Experimental Test 1-Irradiance Change: The experimental test consisted of an abrupt solar irradiance change from 1000 to $800 \mathrm{~W} / \mathrm{m}^{2}$ and then back to $1000 \mathrm{~W} / \mathrm{m}^{2}$ in only one of the array simulator. The other SAS was maintained with fixed i-v characteristics corresponding to and irradiance of $1000 \mathrm{~W} / \mathrm{m}^{2}$. The PV arrays power curves for both irradiances are shown in Fig. 7. The reference voltage values are held at $v_{c 1}^{*}=v_{c 2}^{*}=24 \mathrm{~V}$. Fig. 8 shows the evolution of the system's variables during this experimental test, i.e., the capacitor voltages $\left(v_{c 1}\right.$ and $\left.v_{c 2}\right)$, the primary transformer voltage and the injected current $\left(i_{g}\right)$. As can be seen in these figures, after a small transient time, the voltage across the capacitor maintains its reference value, thus confirming a proper voltage regulation in front of irradiance changes. In addition, notice that the output current is always in phase with the grid voltage.

2) Experimental Test 2-Capacitor Voltage Regulation: In the present scheme, no MPPT algorithm was implemented mainly because its time constants are relatively slow compared to the time constants of the dynamics of the power converter. Nevertheless, the following experimental test aims to emulate an MPPT algorithm by varying the reference capacitor voltage connected to the first array simulator every 5 s, i.e., $v_{c 1}^{*}(t)=30 \mathrm{~V}$, $v_{c 1}^{*}(t+5 s)=29 \mathrm{~V}, v_{c 1}^{*}(t+10 s)=28 \mathrm{~V}$. The second reference voltage is held at $v_{c 2}^{*}=28 \mathrm{~V}$ at all time. The entire experimental test is shown in Fig. 9 and Fig. 10. Fig. 9 presents the measurements of the capacitor voltages $\left(v_{c l}\right.$ and $\left.v_{c 2}\right)$, the primary transformer voltage and the injected current $\left(i_{g}\right)$ and the zoom area of the first reference change. Fig. 10 shows the capacitor voltages $\left(v_{c l}\right.$ and $v_{c 2}$ ), the output voltage of the multilevel converter $\left(v_{H T}\right)$, the injected current $\left(i_{g}\right)$ and the zoom are of the second reference change. Notice the smooth overdamped dynamics of both variables related to the fact that the closed-loop poles of the sampled data system are real. This test evidences how the voltage of the first capacitor tracks the voltage reference, whereas the voltage of the second one remains unchanged to its 
reference value. In addition, the experimental results also show the proper multilevel waveform voltage synthesis. Both tests confirm the proper operation of the system and validate the proposed control design.
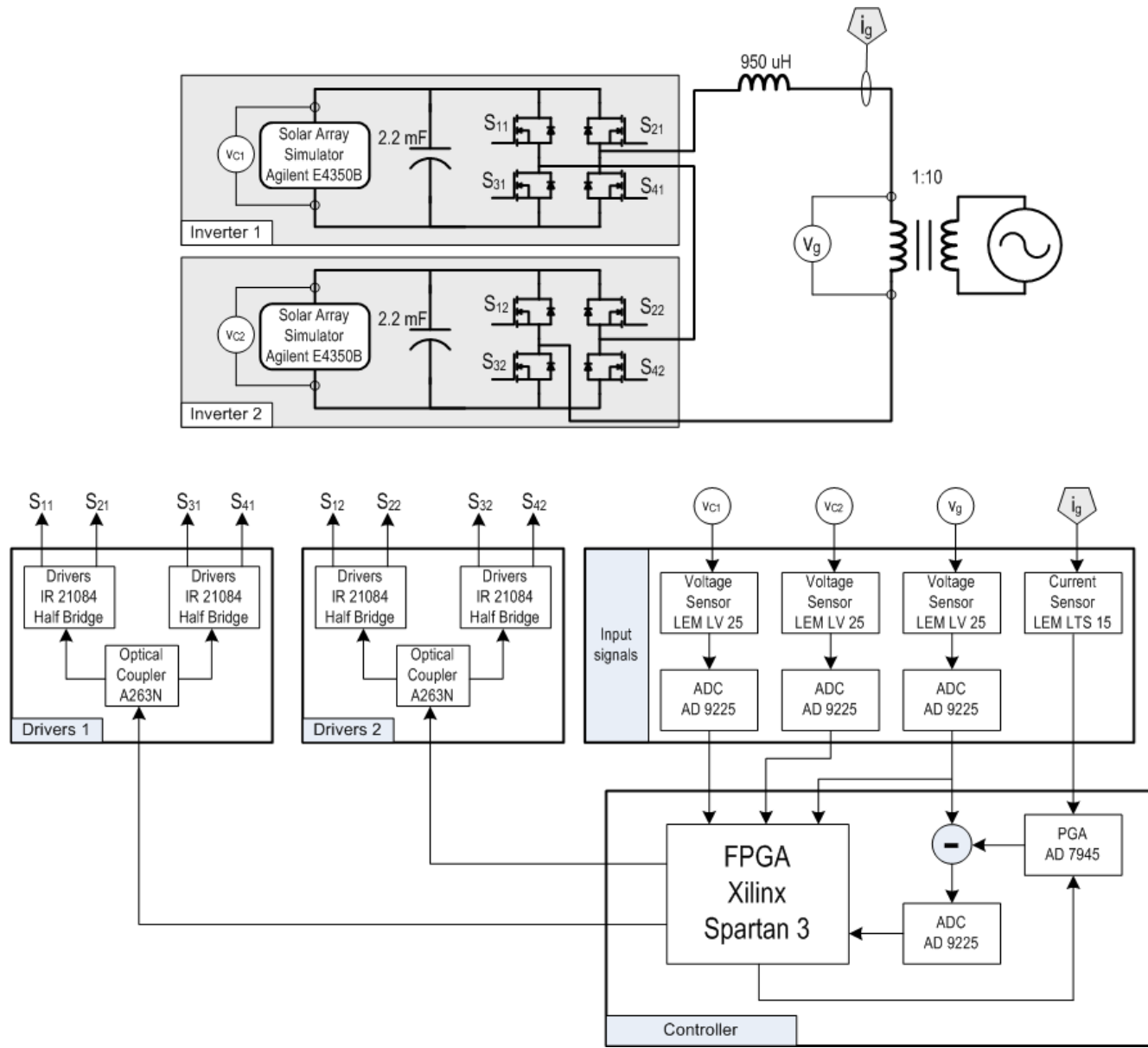

Figure 6. Experimental setup block diagram (ADC=Analog to Digital Converter, PGA=Programmable Gain Amplifier, FPGA=Field Programmable Gate Array)

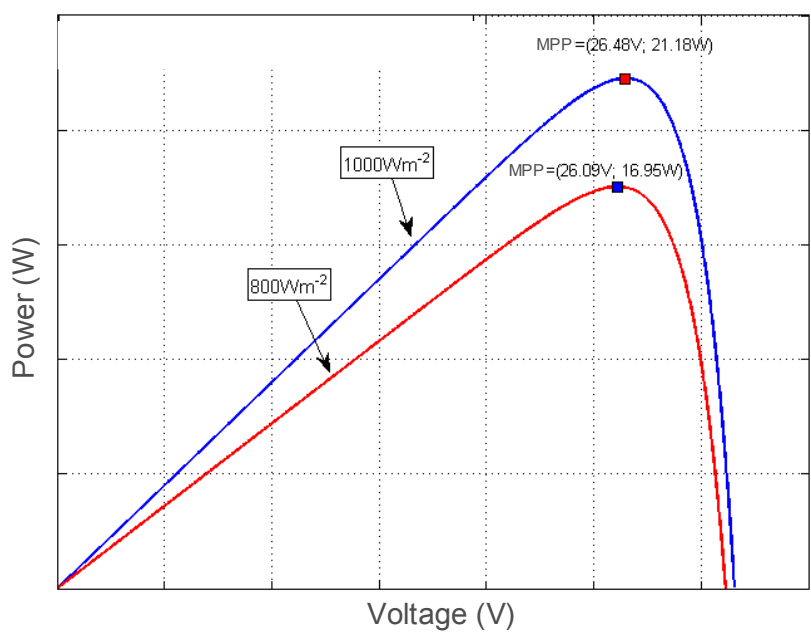

Figure 7. Power versus voltage curves of the experimentally tested PV array (X-axis: $5 \mathrm{~V} / \mathrm{div}, \mathrm{Y}$-axis:5 W/div)

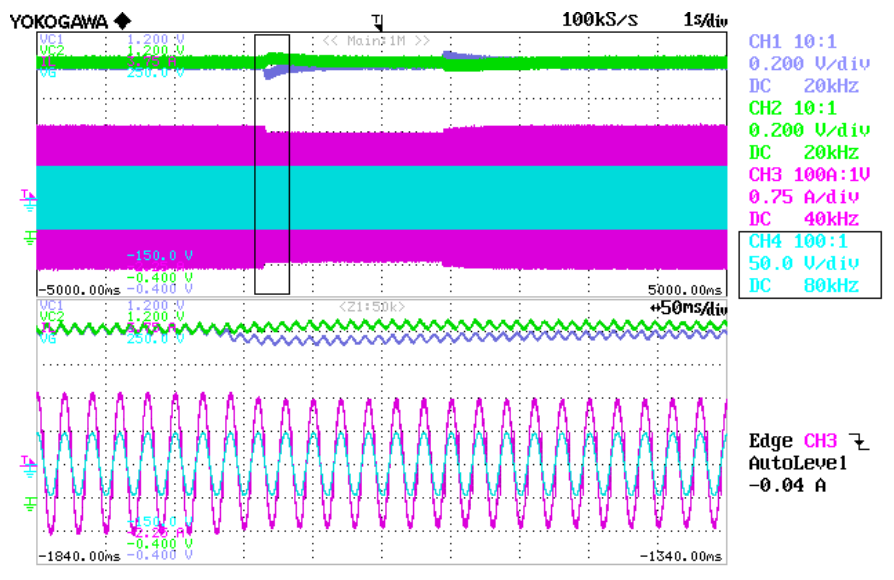

Figure 8. Irradiance change. Capacitor voltages ( $v_{c l}$, green, and $v_{c 2}$, blue), primary transformer voltage (blue) and injected current ( $i_{g}$, magenta). 


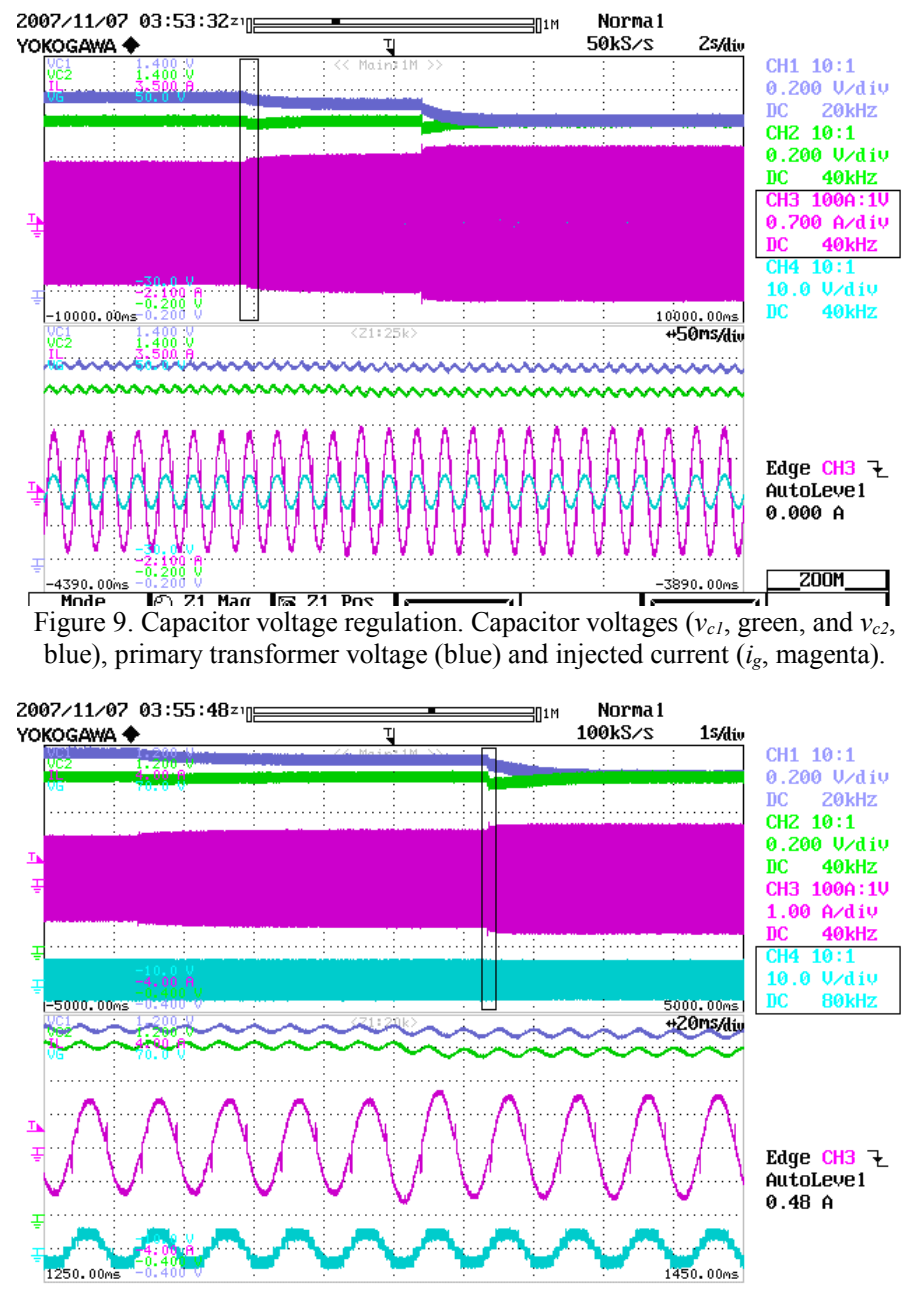

Figure 10. Capacitor voltage regulation. Capacitor voltages ( $v_{c l}$, green, and $v_{c 2}$, blue), output voltage of the multilevel converter $\left(v_{H T}\right.$, blue) and injected current ( $i_{g}$, magenta).

\section{ACKNOWLEDGMENT}

This work was supported in part by the Ministerio de Ciencia e Innovación, Spain, DPI2009-14713-C03-03, DPI2007-62582 by the European Union (FEDER).

\section{REFERENCES}

[1] G. Petrone, G. Spagnuolo, R. Teodorescu, M. Veerachary, and M. Vitelli, "Reliability issues in photovoltaic power processing systems," IEEE Transaction on Industrial Electronics, vol. 55, pp. 2569-2580, 2008.

[2] G. Velasco, J.J. Negroni, F. Guinjoan y R. Piqué. "Some Considerations on Grid-Connected PV Systems Under Partial Shadowing Operation”. XI Seminario Anual de Automática, Electrónica Industrial e Instrumentación, 2004. (SAAEI 04). Toulouse (Francia), Septiembre de 2004. ISBN: 2907801-06-6.

[3] M. Calais, J. Myrzik, T. Spooner, V. G. Agelidis, "Inverter for SinglePhase Grid Connected Photovoltaic Systems - An Overview", PESC, Vol. 4, pp. 1995-2000, Feb. 2002.

[4] M. Calais, V. G. Agelidis, and M. Meinhardt, "Multilevel Converter for Single-phase Grid-connected Photovoltaic Systems: An Overview," Solar Energy, Vol. 66, No. 5, pp. 325-335, 1999.
[5] O. Alonso, P. Sanchis, E. Gubía, and L. Marroyo, "Cascade H-Bridge Multilevel Converter for Grid Connected Photovoltaic Generators with Independent Maximum Power Point Tracking of each Solar Array," Power Electronics Specialists Conference, 2003, pp.731-735.

[6] J. Rodriguez, J. S. Lai, F. Z. Peng, "Multilevel Inverters: A Survey of Topologies, Controls, and Applications", IEEE Trans. On Industrial Electronics, Vol. 49, n 4, pp. 724-738,Aug. 2002.

[7] C. Meza, J.J. Negroni, D. Biel, F. Guinjoan, "Energy-balance modelling and discrete control for single-phase grid-connected PV central inverters," IEEE Transaction on Industrial Electronic, 2008.

[8] J.J. Negroni, F. Guinjoan, C. Meza, D. Biel, P. Sanchis, "Energy-sampled data modeling of a cascade H-bridge multilevel converter for gridconnected PV systems, $10^{\text {th }}$ IEEE International Power Electronics Congress, 2006.

[9] K.H. Hussein, I. Muta, T. Hoshino, M.Osakada. "Maximum photovoltaic power tracking: an algorithm for rapidly changing atmospheric conditions", IEE Proceedings on Generation, Transmission and Distribution, Vol 142, No.1, pp. 59-64, January 1995.

[10] D. Biel, G. Guinjoan, E. Fossas, J. Chavarria, "Sliding-Mode Control Design of a Boost-Buck Switching Converter for AC Signal Generation ", IEEE Trans. On Circuits and Systems, Vol. 55, No. 8, pp. 1539-1551, 2004. 